Conclusion: There are various factors that may affect outcome of limb salvage surgery. Prompt action preoperatively to shorten the ischemic time is very crucial. Early graft occlusion is the most independent risk factor that predicts limb loss. MESS score may give a useful guide to the outcome of arterial repair post trauma.

\title{
CORRELATION BETWEEN SEVERITY OF EROSIVE REFLUX ESOPHAGITIS AND ITS MANOMETRIC FINDINGS IN A TERTIARY HOSPITAL AT EAST COAST, PENINSULAR MALAYSIA. \\ Noor Ezmas $\mathbf{M}^{1}$, Sahrol Azmi $T^{2}$, Nasser $A^{1}$, Junaini $K^{1}$
}

${ }^{1}$ Department of Surgery, Kulliyah of Medicine, International Islamic University Malaysia, Jalan Hospital, 25210 Kuantan.

${ }^{2}$ Pahang State Health Department, Bandar Indera Mahkota, 25200 Kuantan.

Introduction: The burden of Gastroesophageal Reflux Disease, GERD in Asia-Pacific region is increasing.

Objectives: To evaluate the manometric finding in erosive reflux esophagitis and its correlation with severity among patients who were seen at Surgical Department, Hospital Tengku Ampuan Afzan (HTAA), Kuantan.

Methodology: This was a cross sectional study which involved 60 patients seen from September 2012 until January 2014. Patients were required to fill up the Reflux Disease Specific Questionaire and subsequently underwent manometric evaluation. Descriptive statistics and Pearson's correlation were applied using SPSS version 18.0.

Results: There was no correlation between the severity of Erosive Reflux Disease with the Lower Esophageal Sphincter Pressure or esophageal motility. There was positive correlation $(r=+0.54)$ between severity of Erosive Reflux Disease and velocity variables of esophageal motility but it was not statistically significant.

Discussion: Few experts opined that Erosive Reflux Disease is associated with esophageal dysmotility but there was no specific pattern of esophageal mean wave amplitude in our study sample. The limitation of this study was the sample's selection and size. Thus, we need further study with better methodology and sample size.

Conclusion: In conclusion, there was no significant correlation between the severity of Erosive Reflux Esophagitis on the Lower Esophageal Sphincter pressure and the esophageal motility.

\section{Case study}

\section{PROBOSCIS LATERALIS; NASAL APLASIA WITH COMPLETE AGENESIS OF MAXILARY} AND ETHMOIDAL SINUSES: CASE REPORT

Shamim Raman ${ }^{1}$, Yahia F Hussein ${ }^{1}$, Raman Rajagopalan ${ }^{2}$

${ }^{1}$ Department of Otorhinolaryngology, International Islamic University Malaysia, Kuala Lumpur, Malaysia. ${ }^{2}$ Department of Otorhinolaryngology, University Malaya, Kuala Lumpur, Malaysia.

We report a child with Proboscis Lateralis with nasal aplasia and complete agenesis of maxillary and ethmoidal sinuses. This is a rare congenital malformation. Embryological basis has not been proven. It is often associated with facial malformation. However in our patient there was no such abnormality noted. This condition is diagnosed clinically and confirmed radiologically for which CT scan plays a pivotal role. Reconstructive surgery is planned at the age of 15 years.

\section{ALTERNATIVE SURGICAL APPROACH TO CREATE OSTEOMYELITIS IN NEW ZEALAND WHITE RABBIT MODEL \\ Ahmad Hafiz Zulkifly, Aziah Abdul Aziz, Nurul Hafiza Mohd Jan and Mohd Zulfadzli Ibrahim.}

Department of Orthopaedic, Traumatology and Rehabilitation, Kuliyyah of Medicine, International Islamic University Malaysia(IIUM),Jalan Hospital Campus, 25150 Kuantan, Pahang, Malaysia 